\title{
Clause types and speech acts in speech to children
}

\section{Anissa Zaitsu, Jad Wehbe, Valentine Hacquard \& Jeff Lidz*}

\begin{abstract}
The question of how and when children learn to associate clause type with its canonical function, or speech act, is currently unknown. It is widely observed that declaratives tend to result in assertions, interrogatives in questions, and imperatives in requests. Although these canonical links between clause type and speech act are principled, they are known to be defeasible. In this corpus study, we investigate how parents talk to their children in the first years of life, and ask how their input might support this mapping, and to what extent it might pose difficulties. We find that the expected link between clause type and speech act is robust in the input, particularly between declaratives and assertions, both of which also occur most frequently. In addition, the non-canonical mappings that do occur are characterized formally, e.g., non-interrogative questions nearly always exhibit rising prosody, and non-imperative requests often contain a modal.
\end{abstract}

Keywords. corpus-study; pragmatics; syntax; acquisition; clause types; speech acts

1. Introduction. Clause types are said to exist in all languages, and are determined either morphologically, syntactically, or in combination with one another, forming the basic categories: declarative, interrogative, and imperative (Sadock \& Zwicky 1985). Each clause type has what some have called a 'default' function in context (Roberts 2018): declaratives typically express assertions, interrogatives typically pose questions, and imperatives typically issue a directive, or what we neutrally refer to as a request. While principled links between clause types and speech acts exist, the correlation is defeasible; for example, a declarative might make a request, or pose a question. Given this, one might ask when and how children come to identify the clause types of their language, and their default functions. The literature does not provide a clear answer to this. We know that by 12 months children can distinguish formal properties of the clause types declarative and interrogative (e.g., Geffen \& Mintz 2015) and by age 3, have associated clause type with its canonical speech act (e.g., Rakoczy \& Tomasello 2009). But when exactly does this knowledge come on line, and how?

Previous work suggests that distinguishing clause types may be crucial for the acquisition of basic syntactic properties of one's language, argument structure and word meanings before their second birthday (Pinker 1984, Pinker 1989, Gleitman 1990, Gleitman et al. 2005, Perkins 2019). Knowledge of declarative clauses, in particular, would be useful early on, as they are 'basic' in a sense, in that they might establish a baseline with respect to word order and argument structure in a language, which is certainly true of English. Figuring out what the relevant clause types are, however, is not trivial. Languages typically employ a wide range of clausal constructions-actives, passives, imperatives, polar and wh-interrogatives, clefts, pseudoclefts, relative clauses, and so on. Nonetheless, many of these distinctions are collapsed from the perspective of clause typing. For

*We would like to thank Dan Goodhue, Laurel Perkins, Alexander Williams, and Yu'an Yang for helpful discussion and feedback. Authors: Anissa Zaitsu, Stanford University (azaitsu@stanford.edu), Jad Wehbe, MIT (jadwehbe@mit.edu), Valentine Hacquard, University of Maryland (hacquard@umd.edu) \& Jeff Lidz, University of Maryland (jlidz@umd.edu). 
instance, verbs that select for declarative complements do not distinguish between actives, passives and clefts. Children, then, need to cluster the right morphosyntactic properties that are relevant for clause types and associate them with the right pragmatic function.

To start addressing how children might make this association, we investigate how parents speak to their children through a corpus study that examines both the range of clause types and speech acts parents use, and ask whether the two align in the ways we expect. We focus on ages 1 to 3 , since this is the period during which children likely associate clause type and speech act, to see what components of the input support this mapping, and identify where there might be bottlenecks. We ask, in particular, whether parents' speech changes over time, as children's language develops, and they become increasingly able to advance and recognize conversational goals. For example, parents might be less likely to ask questions when children can't respond, which could affect when children link interrogatives to questions.

Our results show that the mapping between clause type and speech act is relatively stable in the child's input; each clause type is mostly used for its default function. We find that overall, declaratives are the most frequent clause type, and that assertions are virtually always made with a declarative. Together, this suggests that children could identify declaratives as basic early on, which would aid them in the ways alluded to above. Questions and requests, compared to assertions, are more varied in terms of the forms that express them. However, in such cases, we find stable indicators of a mismatch. For example, rising prosody tends to mark non-interrogative questions, and modals tend to mark non-imperative requests. Finally, the rate at which each clause type and speech act occur across the ages also remains relatively stable, except for Wh-questions, which surprisingly, occur more in the first year of life than in both the second and third. The input then supports a view on which children use the link between clause types and speech acts to learn the form and function of the clause types.

2. Background. One of the difficulties in formal work on clause types and speech acts is providing the right semantics, usually referred to as the mood, for each clause type such that clause type doesn't fully determine speech act (Roberts 1996, Portner 2004, Farkas \& Bruce 2010, Starr 2014, Krifka 2017, Murray \& Starr 2020, a.o.), but that it still lets us understand why we find the principled links that we do. For example, while a declarative typically makes an assertion, it might also make a request: "You have to leave," and famously, interrogatives, which typically pose a question, might also function as a request, "Can you pass the salt?” (Searle 1975).

A prominent view of speech acts holds that the distinctions among each speech act lies in what they propose to their interlocutors. On Roberts' (2018) view, an assertion involves proposing adding the content of $p$ (some proposition) to the Common Ground (Stalnaker 1978). A request proposes that interlocutors adopt intentions to make $p$ true. A question proposes that the interlocutors collectively commit to collaborative inquiry with respect to $p$. The kinds of proposals each clause type can make are constrained by the semantic content of $p$, and the mood operator characteristic of each clause type. The declarative mood denotes a proposition, which naturally lends itself to assertions, which assert $p$. Interrogative clauses denote a set of propositions, which explains why they invite collaborative inquiry over a set of alternatives. The semantic type for imperatives has been more widely debated, but one view, which will suffice for our purposes is that they denote a property indexed to the addressee and targets the priorities of that addressee (Portner 
2004, 2007, Roberts 2004, Starr 2020).

It has been established that by age 3, children have properly linked declarative clauses with assertions, imperatives with requests, and that they properly answer interrogatives, suggesting an understanding of them (Rakoczy \& Tomasello 2009). Still, it is unclear how and when they make this link between clause type and speech act.

We know that very early on, infants can track the state of knowledge of the people around them, as well as their goals and intentions, including their referential intentions (Woodward 1998, Onishi \& Baillargeon 2005, Kovács et al. 2014, Martin et al. 2012). We also know that young infants show remarkable abilities to track formal properties of the utterances they hear (Saffran et al. 1996, Gómez \& Gerken 2000, Mintz 2002). Through distributional analysis, the child can identify clusters of syntactic features that often co-occur and are good indications of clause type. Geffen \& Mintz $(2015,2017)$ argue that formally, children distinguish declaratives from interrogatives from around 12 months. But children need to further figure out which clause type is which, that is, its primary function. This is where speech act information could be crucial.

We want to know what information children have available to them to make this link, which is in place by 3 and what, if any, difficulties might arise as a function of their input. For example, we know that the link between clause type and speech act is not absolute, but we don't yet know to what extent non-canonical mappings actually occur in natural speech to children. Were they to be very frequent, this could pose a difficulty for the child trying to establish each clause type's basic function. We also want to know whether utterances which do not conform to the default clause type speech act mapping have regularities which the child might be able to track and recognize as exceptions to the rule.

3. Procedure. We examined 15,243 parent utterances from the Providence portion of CHILDES (Demuth et al. 2006) from ages 1;00 to 3;07. This consisted of 5 parent-child pairs who were recorded in both audio and visual formats during unstructured play-time regularly over a period of three years. For each pair, 1,000 parent utterances were annotated per age group: 1;00-1;11 ("1-year olds"), 2;00-2;11 ("2-year olds"), 3;00-3;11 ("3-year olds"), which resulted in roughly 3,000 utterances per parent-child pair.

Each utterance was marked for clause type: DECLARATIVE, INTERROGATIVE, and IMPERATIVE.

(1) a. Johnny picked the flowers.

DECLARATIVE

b. Did Johnny pick the flowers?

INTERROGATIVE

c. What did Johnny pick?

INTERROGATIVE

d. Pick the flowers.

IMPERATIVE

Declaratives are marked in English by the presence of a subject and agreement on the verb, interrogatives are marked by Subject-Auxiliary-Inversion (SAI) or by a left-edge Wh-phrase, and imperatives are marked by the absence of a subject and no tense marking on the verb. In addition, the marginal clause type EXCLAMATIVE was used to mark Wh-exclamatives (reminiscent of exclamatives described in Rett 2011):

(2) What a super idea!

EXCLAMATIVE 
In naturalistic data, there are also many utterances which do not meet any of the criteria just described. We used the tag FRAG as a catch-all for sub-sentential utterances:

(3) a. good boy. $\quad$ FRAG

b. nice of you. $\quad$ FRAG

c. alright like that. FRAG

In addition to clause type, we also marked utterances for speech act. Speech acts were coded according to what the annotator intuited the parent to be doing with the utterance. We view speech acts as proposing to update the context in a particular way. That is, utterances which attempt to give the child information were marked as ASSERTION; utterances that offer the child some sort of direction were marked as REQUEST; utterances which invite collaborative inquiry were marked as QUESTION; and utterances which express some degree of surprise for $p$ were marked as EXCLAMATION.

Each utterance was coded by one of the two annotators (the first authors on this paper). $10 \%$ of the corpus coded by both annotators to check for reliability. We checked for inter-annotator agreement on speech act, which was high (Cohen's kappa $=.92$ ). The rest of the corpus was coded by one of the two annotators. Because of the audio/visual format of the corpus, it was easy to detect intonation, and to see how the child reacted to the parents' utterances, providing a way to reasonably determine the intended speech act.

Below are examples of what we would call a MATCH; that is, the clause type used results in the expected speech act:

(4) a. Is this turned on?

INTERROGATIVE-QUESTION

b. Go get the other one.

IMPERATIVE-REQUEST

c. That's the photograph book we made.

d. What a good fish face!

DECLARATIVE-ASSERTION

EXCLAMATIVE-EXCLAMATION

Certain FRAG utterances were also marked as having a speech act if the annotator was able to discern a full VP; that is, a predicate with its internal argument or a bare V if intransitive.

(5) a. Saw a lot of them earlier.

FRAG-ASSERTION

b. See the shovel?

FRAG-QUESTION

c. May have to do it to other way.

FRAG-REQUEST

(5-a) is missing a subject, but the past tense marking clearly rules it out as an imperative clause. In (5-b), a subject is missing once again, and while there's no tense marking on the verb, the utterance is marked by rising intonation. The verb in (5-b) is also the perception verb see, which does not have an agent and cannot be used as an imperative. In (5-c), a subject is missing, but there are two modals above the VP, which means it cannot be an imperative clause, and provides enough information to see that (5-c) expresses a REQUEST.

We also find variety of mismatches involving full clauses, a subset of which are presented below. A MISMATCH is defined as a clause that does not result in its default speech act.

(6) a. You have to go forwards.

DECLARATIVE-REQUEST

b. Can you move your foot please?

c. Oh my gosh look at all those babies!

INTERROGATIVE-REQUEST

IMPERATIVE-EXCLAMATION 
The IMPERATIVE-EXCLAMATION seen in (6-c) wasn't very common, but it's clear in context that they do not direct their addressee, and instead meet the criteria for EXCLAMATION. In the context that (6-c) occurs, the child is showing the parent several baby dolls, which does not support a directive use of the imperative form.

In addition to clause type and speech act information, annotators also coded for various grammatical aspects of the utterance. Various features of the subject were marked, as were modals, embedding verbs, and negation. This was done in order to trace in regularities in mismatches, to be discussed in the following section. Lastly, utterances were also marked for intonation - this helped to identify questions across clause type.

The form of polar questions and the function of Wh-elements proved to be fairly diverse in the input, which required further elaboration of the annotation schema. Polar questions are those which ask whether $p$ or its negation holds. Although rising declaratives (RD) have a similar effect in terms of introducing alternatives $p$ and its negation, they are said to introduce an additional bias for one of the alternatives (Gunlogson 2008, Malamud \& Stephenson 2015, Farkas \& Roelofsen 2017). Whether they are fundamentally declarative in mood or interrogative has recently been taken up (Farkas \& Roelofsen 2017, Malamud \& Stephenson 2015, Jeong 2018). We do not take a theoretical stance here, but we did mark them with DECLARATIVE clause type and additionally marked them for rising intonation - they were also given a speech act, which usually (but not always) turned out to be QUESTION, and thus were counted as a MISMATCH. However, under certain approaches (e.g., Farkas \& Roelofsen 2017), characterizing a RD as a MISMATCH wouldn't be wholly accurate, since rising declaratives are viewed as having interrogative mood.

In addition, there were several truncated clauses that had a polar question type meaning and the associated rising intonation, which we marked as Left Edge Ellipsis (LEE). In some cases, only an auxiliary was elided, which left the subject and the VP. In others, both a subject and an auxiliary were missing, leaving the VP. Some were ambiguous between LEE and RD, which we called RD-POSS. This occurred when there was a 2 nd person subject followed by an untensed verb. In English, agreement with a 2nd person pronoun is null, so it's not possible to tell whether an auxiliary was elided at the left edge or not.

(7) a. You're going to open the door?

RD-DEF

b. You want your ball?

RD-POSS

c. You kissing that baby too? LEE

d. Wanna go on your swing? LEE

e. Do you want your ball?

PQ

In (7-a), the auxiliary expressed in its contracted form clearly marks the clause as a rising declarative (RD-DEF), since we can see that no SAI has occurred. On the other hand, the string in (7-b) corresponds to possible declarative clause in English, but the absence of an auxiliary raises an ambiguity. (7-b) could underlying be (7-e), with auxiliary do elided at the left edge, hence the tag RD-POSS for possible RD. That such a possibility is available in the language is evidenced by the existence of examples such as (7-c). The -ing marking on verbs is only licensed by a particular kind of auxiliary be in English, i.e., You kissing that baby too is not a possible declarative in English. In that case, we can be sure that some element which is doing the licensing for that form is not pronounced. The same process could be at work in (7-b). We marked both RD-DEF and RD-POSS 
as having DECLARATIVE clause type, and we marked both kinds of LEE as FRAG.

Wh-questions (WH-Q), on the other hand, were typically expressed as full clauses. There were a minority of fragment utterances that contained a Wh-element, however. There were what some might call 'root sluices' - that is, a Wh-phrase related to some correlate in an antecedent provided in context. There was also a conventionalized 'What?' where the parent generally meant, What did you say?, or a conventionalized 'Which one?' meaning Which one are you talking about? Also surfaced were What-about-DP and How-about-XP utterances that seem to be conventionalized to direct the child's attention to some object or to make a suggestion. Although a full VP was not always present in these cases, the contribution of the conventionalized aspect of these and the Wh-element used made it possible to discern various speech acts. For that reason, fragment Wh-questions were also given a speech act.

(8) a. How about putting them on this side now?

FRAG-REQUEST

b. What about elephants?

FRAG-QUESTION

c. What, honey? (=What did you say?)

d. Which one? (=Which one are you talking about?)

FRAG-QUESTION

FRAG-QUESTION

Very little work currently exists on What-about and How-about type questions, so it's hard to say anything about how to interpret these data. But they seem to have a rather flexible discourse use, usually functioning as a suggestion, a question, and sometimes, even, an answer to a question.

\section{Corpus data.}

4.1. INPUT BY AGE. The data collected allow us to look at various syntactic, semantic, and pragmatic features of the child's input. We can start by establishing a baseline for the clause types children hear across each age group, allowing us to track whether the input changes. In Table 1 below, we divide DECLARATIVE by FALL and RISE to indicate intonation, and INTERROGATIVE by WH and POLAR.

\begin{tabular}{|c|c|c|c|c|c|c|}
\hline & \multicolumn{2}{|c|}{ DECLARATIVE } & \multicolumn{2}{|c|}{ INTERROGATIVE } & \multirow[t]{2}{*}{ IMPERATIVE } & \multirow[t]{2}{*}{ TOTAL } \\
\hline & FALL & RISE & WH & POLAR & & \\
\hline 1 YEAR OLDS & $1281(45.2 \%)$ & $134(4.7 \%)$ & $605(21.3 \%)$ & $304(10.7 \%)$ & $512(18.1 \%)$ & $2836(100 \%)$ \\
\hline 2 YEAR OLDS & $1806(55.7 \%)$ & $199(6.1 \%)$ & $362(11.2 \%)$ & $373(11.5 \%)$ & $502(15.5 \%)$ & $3242(100 \%)$ \\
\hline 3 YEAR OLDS & $1821(57.5 \%)$ & $151(4.8 \%)$ & $339(10.7 \%)$ & $306(9.7 \%)$ & $550(17.4 \%)$ & $3167(100 \%)$ \\
\hline TOTAL & $4908(53 \%)$ & $484(5.2 \%)$ & $1306(14.1 \%)$ & $983(10.6 \%)$ & $1564(16.9 \%)$ & $9245(100 \%)$ \\
\hline
\end{tabular}

Table 1: Clause type by age

The table above, in part, confirms the intuition that declarative clauses are 'basic.' Across all ages, declarative clauses make up the majority of full clauses. Wh-questions are the next most common clause type only for 1-year-olds, making up $21.3 \%$ of the full clauses they hear in this sample. That number decreases by $10 \%$ by the second year of life. Conversely, the rate of falling declaratives increases by $10 \%$ by the second year of life. Otherwise, the numbers across the other clause types stay relatively stable across all ages.

We can also view how speech acts changed across the ages, which largely tracks the changes 
we see in the clause types, foreshadowing that the two are dependent, as expected. Below, we show Table 2, which takes into account all speech acts, even those with the FRAG clause type. We also include distinctions among the different kinds of questions: Wh, polar, and those which were either of the form RD or LEE, which might function differently in their associated context of utterance from basic polar questions made with interrogative syntax.

\begin{tabular}{lcccccc}
\hline & ASSERTION & \multicolumn{3}{c}{ QUESTION } & REQUEST & TOTAL \\
\hline & \multicolumn{1}{c}{ WH } & POLAR & RD/LEE \\
\hline 1 YEAR OLDS & $1255(40.8 \%)$ & $650(21.2 \%)$ & $230(7.5 \%)$ & $236(7.7 \%)$ & $701(22.8 \%)$ & $3072(100 \%)$ \\
\hline 2 YEAR OLDS & $1736(50.7 \%)$ & $410(12 \%)$ & $321(9.4 \%)$ & $251(7.3 \%)$ & $707(20.6 \%)$ & $3425(100 \%)$ \\
\hline 3 YEAR OLDS & $1770(53 \%)$ & $395(11.8 \%)$ & $265(7.9 \%)$ & $214(6.4 \%)$ & $694(20.8 \%)$ & $3338(100 \%)$ \\
\hline
\end{tabular}

Table 2: Speech act by age

We find, also, that there is general stability in terms of speech acts across the ages. Assertions are always the most frequent in the child's input, which seems to track with DECLARATIVE across the ages. ASSERTION increase by $\% 10$ in speech to 2 years old versus speech to 1 year olds, while Wh-questions decrease by $10 \%$ during this period. Taking all the various question types together, they are the next most common speech act, making up about $36 \%$ of the input at age 1, 29\% at age 2 , and $26 \%$ at age 3 . Thus, it does not seem to be true that parents use fewer questions in the earlier years of life, even though children's ability to accurately understand and respond may not yet be in place. We see, instead, that the opposite is true. Parents use more questions in the earlier years of life, and use more assertions as time goes on.

4.2. Clause type AND SPEeCH aCt MAPPing. We can now turn to the mismatches between clause type and speech act, which can be viewed in two ways. First, we can assess the rate at which each speech act was performed by each clause type. That is, how often an ASSERTION was made with a DECLARATIVE, or a QUESTION with an INTERROGATIVE, and so on. We expect to see a tight link between clause type and speech act, given the view that each clause type has a particular semantic make up that gives rise to tendencies among which speech acts they perform. We see this borne out in Table 3, below.

\begin{tabular}{c|c|c|c|c}
\hline & ASSERTION & QUESTION & REQUEST & EXCLAMATION \\
\hline DECLARATIVE & $4643(97.4 \%)$ & $458(15.3 \%)$ & $289(15.3 \%)$ & $2(5 \%)$ \\
INTERROGATIVE & $18(0.4 \%)$ & $2074(69.2 \%)$ & $195(9 \%)$ & $2(5 \%)$ \\
IMPERATIVE & 0 & 0 & $1543(73.8 \%)$ & $21(52.5 \%)$ \\
EXCLAMATIVE & 0 & 0 & 0 & $13(32.5 \%)$ \\
FRAG & $100(2 \%)$ & $440(15.4 \%)$ & $75(2.9 \%)$ & $2(5 \%)$ \\
TOTAL & $4761(100 \%)$ & $2972(100 \%)$ & $2102(100 \%)$ & $40(100 \%)$ \\
\hline
\end{tabular}

Table 3: Percentage of each clause type given the speech act

The most stable link from this perspective is that between speech act ASSERTION and DECLARATIVE. Assertions are not readily performed by any of the other clause types. This data point, once 
again, seems to confirm that DECLARATIVE clauses are 'basic,' and should be easily acquirable from the input, particularly if one holds the view that children use this information to learn the clause types of their language.

The very few utterances marked as INTERROGATIVE-ASSERTION either involved a question with high preposed negation, indicating speaker bias for $p$, or involved an embedded clause, which seemed to be asserted in a clause that was polar in the root clause.

(9) a. Isn't that nice?

b. Did you know that some birds can learn to say words?

In these cases, the annotator judged the parent to be proffering the $p$, that's nice in (9-a), and to be proffering the $p$ of the embedded clause in (9-b), which meets the criteria for ASSERTION. It should be noted that not all instances of biased polar questions, nor instances of embedded propositions under a root polar interrogative were judged as ASSERTION - these are embedded within particular contexts that gave rise to such judgements.

We see, also, of course, that the other core speech acts, QUESTION, and REQUEST are associated significantly with their expected clause type, though with a greater degree of variability than ASSERTION. We will discuss the properties that characterize these mismatches individually in the following sections. But we should note here before moving on that DECLARATIVE make up 15\% of all mismatches involving QUESTION, and another $15 \%$ of all mismatches involving a REQUEST, foreshadowing that while an ASSERTION is the least variable speech act, DECLARATIVE might be the most variable clause type.

To address this, we can also look at the percentages from the perspective of the clause type. In other words, how often was each clause type used to perform the various speech acts? The data presented below in Table 4 will reveal an interesting asymmetry. On one hand, an ASSERTION is rarely made with any other clause type but a DECLARATIVE, and on the other, DECLARATIVE turn out to be the most diverse in terms of the speech acts they express.

\begin{tabular}{cccccc}
\hline & ASSERTION & QUESTION & REQUEST & EXCLAMATION & TOTAL \\
\hline DECLARATIVE & $4643(86.1 \%)$ & $458(8.5 \%)$ & $289(5.4 \%)$ & $2(.03 \%)$ & $5392(100 \%)$ \\
\hline INTERROGATIVE & $18(0.9 \%)$ & $2074(90.5 \%)$ & $195(8.3 \%)$ & $2(.9 \%)$ & $2289(100 \%)$ \\
\hline IMPERATIVE & 0 & 0 & $1543(98.7 \%)$ & $21(1.3 \%)$ & $1564(100 \%)$ \\
\hline EXCLAMATIVE & 0 & 0 & 0 & $13(100 \%)$ & $13(100 \%)$ \\
\hline FRAG & $100(16.5 \%)$ & $440(72.8 \%)$ & $75(10.2 \%)$ & $2(0.3 \%)$ & $617(100 \%)$ \\
\hline
\end{tabular}

Table 4: Percentage that a clause type resulted in each speech act

The link between DECLARATIVE and ASSERTION is still significant from this perspective, but flips to being the most variable cell of the table. The next most variable clause type is INTERROGATIVE, which result in a REQUEST in $8.3 \%$ of utterances. The most stringent clause type is an IMPERATIVE, which nearly always results in a REQUEST - the few exceptions being IMPERATIVEEXCLAMATION instances discussed earlier. 
4.3. REQUESTS. In this section, we take a closer look at what characterizes a REQUEST that was not made with an IMPERATIVE. Requests were made with an IMPERATIVE about $74 \%$ of the time. The other $26 \%$ were split between DECLARATIVE clauses, which amounted to $15 \%$ of the requests, and another $9 \%$ were made with an INTERROGATIVE. One pattern we identify in Table 5 below is that most non-IMPERATIVE requests contain a modal.

\begin{tabular}{ccccccc}
\hline & \multicolumn{2}{c}{ DECLARATIVE } & TOTAL & \multicolumn{2}{c}{ INTERROGATIVE } & TOTAL \\
\cline { 2 - 3 } & MOD & NO MOD & & MOD & NO MOD & \\
\cline { 2 - 3 } ASSERTION & $838(18 \%)$ & $3805(82 \%)$ & $4643(100 \%)$ & $2(11 \%)$ & $16(89 \%)$ & $18(100 \%)$ \\
\hline QUESTION & $23(5 \%)$ & $435(95 \%)$ & $458(100 \%)$ & $233(11 \%)$ & $1841(89 \%)$ & $2074(100 \%)$ \\
\hline REQUEST & $169(58 \%)$ & $120(42 \%)$ & $289(100 \%)$ & $143(73 \%)$ & $52(27 \%)$ & $195(100 \%)$ \\
\hline
\end{tabular}

Table 5: Modals across clause type and speech act

Utterances marked as DECLARATIVE-ASSERTION, which constitute a MATCH, only contain a modal $18 \%$ of the time. A DECLARATIVE-QUESTION also very rarely contains modals. However, most DECLARATIVE-REQUEST contain a modal, at 58\%. This suggests that modals are a good predictor for this type of MISMATCH, and if tracked by the child, might provide a cue that the clause they encountered has a special function, i.e., is not an ASSERTION. The other $42 \%$ of DECLARATIVE-REQUEST without a modal are usually made with a 2nd person pronoun (82\%), and with no tense marking on the verb.

(10) a. You just give it a little dip.

b. You take it with you.

c. You line them up.

Annotators did not specifically code for tense marking, but it's possible that this, in combination with 2nd person pronouns is also a good predictor of DECLARATIVE-REQUEST. However, one would need to see how often such a frame occurred in DECLARATIVE-ASSERTION, and so on.

Table 5 also shows the distribution of modals in INTERROGATIVE clauses, where modals occur in $73 \%$ of those marked INTERROGATIVE-REQUEST. The other two potential mappings skew the other way, in mostly not containing modals. So while INTERROGATIVE-REQUEST make up a relatively small percentage of the mismatches involving REQUEST, the majority of them have a modal that could potentially be tracked - and that same feature would be useful in tracking mismatches involving a DECLARATIVE as well.

The other $27 \%$ of those marked INTERROGATIVE-REQUEST that do not contain modals also display a particular property. Nearly all of them $(81 \%)$ are a special kind of why-interrogative that involve negation, which together, have a conventionalized meaning:

(11) a. Why don't you use the other bat?

b. So why don't you give it to me?

c. Why don't you stay right there?

Negation is relatively rare in the input overall, and most Wh-questions that have negation are of the above kind, which means that these should stand out to the child. 
What we have here is good evidence that while mismatches do occur between clause type and speech act, good indicators exist that the clause encountered might have a special function; i.e., they tend to deviate from the patterns displayed in a MATCH. Modality, in particular, seems to be especially important in tracking mismatches in both kinds of non-IMPERATIVE requests. It is also true that in formal work, imperative clauses have been identified with modals more broadly, and have even been said to part of the semantic content of the imperative clause type (Kaufmann 2012). From that standpoint, it is then, not surprising that overt modals occur in clauses that ultimately result in a directive force.

4.4. QUESTIONS. In this section, we take a closer look at the most variable speech act, QUESTION. There were several non-INTERROGATIVE clauses that resulted in a QUESTION. 15\% were made with DECLARATIVE clauses, and the other $15 \%$ were made with FRAG utterances.

Utterances marked DECLARATIVE-QUESTION nearly always had rising intonation $-98 \%$ to be exact. The remaining $2 \%$ of utterances marked DECLARATIVE-QUESTION were either instances of clauses with an embedded question that were judged as being placed under discussion, or declarative utterances with tags that were judged to be inquisitive in nature. For example:

(12) a. I wonder who these are.

b. I don't think today, will we?

Embedded questions and utterances with tags were not always marked as QUESTION. It was in these few contexts that annotators judged such structures to be used as a QUESTION.

The majority of those marked as FRAG-QUESTION had rising intonation, and were tagged for Left Edge Ellipsis (LEE), accounting for $58 \%$ of such utterances. The other $42 \%$ were instances with a Wh-element that wasn't attached to a full clause, though had recoverable meaning in context.

Polar questions, in particular, seem to be most variable in terms of the kinds of clauses that express them. In Table 6 below, we will see that less than half of all clauses with polar question meaning, i.e., asking whether $p$ or its negation holds, were made with polar interrogative syntax (e.g., displayed SAI).

\begin{tabular}{|c|c|c|}
\hline Q-TYPE & EXAMPLE & $\operatorname{COUNT}(\%)$ \\
\hline PQ & Are you thirsty? & $808(48.5 \%)$ \\
\hline LEE & $\begin{array}{l}\text { a. Wanna go on your swing? } \\
\text { b. You kissing that penguin? }\end{array}$ & $256(15.3 \%)$ \\
\hline RD-POSS & You put Bob in the pilot? & $242(14.5 \%)$ \\
\hline RD-DEF & You're gonna hit it or throw it? & $202(12.1 \%)$ \\
\hline TAG & $\begin{array}{l}\text { a. We're not really going to the zoo, are we? } \\
\text { b. A dumptruck's on the tracks, huh? } \\
\text { c. You knew that one, right? }\end{array}$ & $158(9.4 \%)$ \\
\hline TOTAL & & $1666(100 \%)$ \\
\hline
\end{tabular}

Table 6: Polar questions in the child's input

Of those utterances that were marked as having a polar question meaning, only $48.5 \%$ of them 
were in the full polar interrogative form seen in the first row of Table $6 .^{1}$ If we collapsed the two RD types, RD-POSS and RD-DEF, rising declaratives make up $26.6 \%$ of polar questions. Instances of LEE make up another 15\%. Most instances of LEE were of the VP type seen in (a) of the second row $-173(67 \%)$; the rest were unambiguously missing an auxiliary at the left edge. Together, RD forms and LEE forms can be unified as having rising intonation, which in turn, unifies them with basic polar interrogatives. Despite the variability in morphosyntactic form, children should have a way of understanding these utterances as a unified class.

However, some languages routinely use rising intonation to indicate polar question meaning, e.g., French. At some point English-learning children need to learn that they are English, and not French. This may not be a trivial task, given that rising declaratives are fairly robust in the input. The function of a rising declarative is generally thought to be somewhat distinct from both a polar question and an assertion, which means such nuances in force will need to be acquired for English-speaking children. Goodhue et al. (2021) show that by age 3, children seem to treat rising declaratives differently from both polar questions and falling declaratives.

5. Discussion. Our corpus study has shown that the mapping between clause type and speech act is fairly stable in speech to children. Each clause type is mostly used to express its default speech act; for the most part, declaratives result in assertions, interrogatives in questions, and imperatives in requests. The same is true from the perspective of the speech act; that is, assertions are nearly always made with a declarative, questions are mostly made with interrogatives, and requests are mostly made with imperatives. We do find variability introduced from this perspective; that is, non-interrogative syntax makes up $31 \%$ of questions, and non-imperative syntax makes up $27 \%$ of requests. We are able to identify, however, that such uses are characterized by certain formal properties. Non-interrogative syntax that results in questions either have rising prosody or a conventionalized use of a bare Wh-element. Non-imperative requests usually have a modal, or a 2nd person pronoun that is subject of a non-past clause.

Across the age groups, 1 year olds, 2 year olds, and 3 year olds, the input stays relatively stable from the perspective of clause type. One caveat is that between 12 months and 24 months (1 year olds), children hear Wh-questions at a greater rate than in any other age range explored here. This is surprising given that their capacity to respond is fairly limited during this time. In that same age range, declarative clauses are used the least relative to the other two age groups. Even so, falling declaratives are the most numerous clause type across all ages.

With this much established, we can now address how children might come to associate clause type with its canonical function. One hypothesis consistent with our results is that children use the mutually constraining information from morphosyntactic properties of the clause type and sensitivity to speaker intention, e.g., the speech act, to learn the mapping between clause type and speech act. We know independently from the acquisition literature that children track the formal properties of utterances they hear (Saffran et al. 1996, Gómez \& Gerken 2000, Mintz 2002). Children are also sensitive to the goals and intentions of their interlocutors (Woodward 1998,

\footnotetext{
${ }^{1}$ To be clear, Table 6 is intended to represent utterances with polar question meaning, i.e., were marked as QUESTION. That means it does not include the forms INTERROGATIVE, LEE, or RD that were marked as REQUEST or ASSERTION. However, because tags were so infrequent overall, we included all such instances in the count above, no matter the speech act they were judged to have.
} 
Onishi \& Baillargeon 2005, Kovács et al. 2014, Martin et al. 2012), which could be used to help them track speech act. Expectations that a language will generally linguistically distinguish the three main speech acts discussed here would likely be useful, and given the universality of clause types and their basic contextual effect, this seems like a plausible prior expectation. Children might further expect that assertions, or utterances that give them information are basic, and that the clause canonically associated with them is, in turn, the most basic clause type, from which they could draw generalizations about word order, argument structure, and recognize various displacements in the language.

Our results suggest that polar questions might be the most difficult to acquire. Less than half of polar questions are made with full interrogative syntax. It is relevant that both kinds of rising declaratives (unambiguous and ambiguous) make up about $26 \%$ of the polar questions they hear. In some languages, intonation plus declarative syntax is one way, and sometimes, the preferred way to form a polar question, e.g., French, Hindi, Brazillian Portuguese. Children might mistakenly think that rising declaratives are another way to form a basic polar question. In English, however, rising declaratives are said to have a special meaning that distinguishes them in some way from polar questions expressed with interrogative syntax. For instance, one one view, RDs are associated with an additional pragmatic effect that combines with the basic contextual effect of an interrogative (i.e., introducing alternatives), creating what often feels like a bias for one of the alternatives introduced (Farkas \& Roelofsen 2017). Goodhue et al. (2021) show that 3 year olds treat polar interrogatives, falling declaratives, and rising declaratives differently. Whether children can make this three way distinction earlier is not yet known, but given the prevalence of RDs in the input and that they may be used where a polar interrogative would also be appropriate, we might expect that at some point along the acquisition trajectory, English-learning children treat rising declaratives and polar interrogatives the same. It's possible also, however, that the frequency with which polar interrogatives (983) occur as opposed to rising declaratives (484) is enough for the child to determine that rising declaratives are a special kind of polar interrogative, which forms the basic case.

6. Conclusion. In this corpus study, we have examined the information that children have available to them in establishing a mapping between clause type and speech act. Before children have fully mastered the syntax of their language, sorting clause types would likely be useful, particularly knowledge of declarative clauses as basic. But how do they do this with a limited portion of their grammar in place? Our results present a possible way forward. We find a particularly strong link between assertion and declarative clauses. Were children equipped with the ability to track speech acts, with prior knowledge that assertions would correspond to the basic clause type in their language, their input would support establishing the mapping early on. Among the other two core mappings, the results are slightly more varied, but our results indicate that non-canonical instances are also principled. This could be useful in two ways: i) children might be able to set aside mismatches because they contain markers that indicate they have an effect different from that typically associated with that clause type, and ii) children might be able to learn the special pragmatics associated with these uses, e.g., rising declaratives are a special kind of biased polar question. The study has also raised some new questions, particularly regarding how English-learning children make sense of the varied forms that polar questions take in the language. 


\section{References}

Demuth, Katherine, Jennifer Culbertson \& Jennifer Alter. 2006. Word-minimality, epenthesis and coda licensing in the early acquisition of English. Language and Speech 49(2). 137-173. https://doi.org/10.1177/00238309060490020201.

Farkas, Donka F \& Kim B Bruce. 2010. On reacting to assertions and polar questions. Journal of semantics 27(1). 81-118. https://doi.org/10.1093/jos/ffp010.

Farkas, Donka F \& Floris Roelofsen. 2017. Division of labor in the interpretation of declaratives and interrogatives. Journal of Semantics 34(2). 237-289. https://doi.org/10.1093/jos/ffw012.

Geffen, Susan \& Toben H Mintz. 2015. Can you believe it? 12-month-olds use word order to distinguish between declaratives and polar interrogatives. Language Learning and Development 11(3). 270-284. https://doi.org/10.1080/15475441.2014.951595.

Geffen, Susan \& Toben H Mintz. 2017. Prosodic differences between declaratives and interrogatives in infant-directed speech. Journal of child language 44(4). 968-994. https://doi.org/10.1017/S0305000916000349.

Gleitman, Lila. 1990. The structural sources of verb meanings. Language acquisition 1(1). 3-55. https://doi.org/10.1207/s153278171a0101_2.

Gleitman, Lila R, Kimberly Cassidy, Rebecca Nappa, Anna Papafragou \& John C Trueswell. 2005. Hard words. Language learning and development 1(1). 23-64. https://doi.org/10.1207/s154733411ld0101_4.

Gómez, Rebecca L \& LouAnn Gerken. 2000. Infant artificial language learning and language acquisition. Trends in cognitive sciences 4(5). 178-186. https://doi.org/10.1016/S13646613(00)01467-4.

Goodhue, Daniel, Jad Wehbe, Valentine Hacquard \& Jeffrey Lidz. 2021. The effect of intonation on the illocutionary force of declaratives in child comprehension. In Proceedings of Sinn und Bedeutung, vol. 25, 1-18.

Gunlogson, Christine. 2008. A question of commitment. Belgian Journal of Linguistics 22(1). 101-136. https://doi.org/10.1075/bj1.22.06gun.

Jeong, Sunwoo. 2018. Intonation and sentence type conventions: Two types of rising declaratives. Journal of Semantics 35(2). 305-356. https://doi.org/10.1093/semant/ffy001.

Kaufmann, Magdalena. 2012. Interpreting imperatives. Springer, Studies in Linguistics and Philosophy 88. https://doi.org/10.1007/978-94-007-2269-9.

Kovács, Ágnes Melinda, Tibor Tauzin, Ernő Téglás, György Gergely \& Gergely Csibra. 2014. Pointing as epistemic request: 12-month-olds point to receive new information. Infancy 19(6). 543-557. https://doi.org/10.1111/infa.12060.

Krifka, Manfred. 2017. Negated polarity questions as denegations of assertions. In Contrastiveness in information structure, alternatives and scalar implicatures, 359-398. Springer. https://doi.org/10.1007/978-3-319-10106-4_18.

Malamud, Sophia A \& Tamina Stephenson. 2015. Three ways to avoid commitments: Declarative force modifiers in the conversational scoreboard. Journal of Semantics 32(2). 275-311. https://doi.org/10.1093/jos/ffu002.

Martin, Alia, Kristine H Onishi \& Athena Vouloumanos. 2012. Understanding the abstract role of speech in communication at 12 months. Cognition 123(1). 50-60. 
https://doi.org/10.1016/j.cognition.2011.12.003.

Mintz, Toben H. 2002. Category induction from distributional cues in an artificial language. Memory \& Cognition 30(5). 678-686. https://doi.org/10.3758/BF03196424.

Murray, Sarah E \& William B Starr. 2020. The structure of communicative acts. Linguistics and Philosophy 1-50. https://doi.org/10.1007/s10988-019-09289-0.

Onishi, Kristine H \& Renée Baillargeon. 2005. Do 15-month-old infants understand false beliefs? Science 308(5719). 255-258. https://doi.org/10.1126/science.1107621.

Perkins, Laurel. 2019. How grammars grow: Argument structure and the acquisition of non-basic syntax: University of Maryland, College Park dissertation.

Pinker, Steven. 1984. Language learnability and language development. Harvard University Press.

Pinker, Steven. 1989. Learnability and cognition: The acquisition of argument structure. The MIT Press.

Portner, Paul. 2004. The semantics of imperatives within a theory of clause types. In Semantics and linguistic theory, vol. 14, 235-252.

Portner, Paul. 2007. Imperatives and modals. Natural language semantics 15(4). 351-383. https://doi.org/10.1007/s11050-007-9022-y.

Rakoczy, Hannes \& Michael Tomasello. 2009. Done wrong or said wrong? Young children understand the normative directions of fit of different speech acts. Cognition 113(2). 205-212. https://doi.org/10.1016/j.cognition.2009.07.013.

Rett, Jessica. 2011. Exclamatives, degrees and speech acts. Linguistics and philosophy 34(5). 411-442. https://doi.org/10.1007/s10988-011-9103-8.

Roberts, Craige. 1996. Towards an integrated formal theory of pragmatics. OSU working papers in linguistics 49.

Roberts, Craige. 2004. Context in dynamic interpretation. In Laurence R. Horn \& Gregory Ward (eds.), The handbook of pragmatics, 155-196. Oxford and Malden, MA: Blackwell.

Roberts, Craige. 2018. Speech acts in discourse context. In New work on speech acts, Oxford University Press Oxford. https://doi.org/10.1093/oso/9780198738831.003.0012.

Sadock, Jerrold M \& Arnold M Zwicky. 1985. Speech act distinctions in syntax. Language typology and syntactic description 1. 155-196.

Saffran, Jenny R, Richard N Aslin \& Elissa L Newport. 1996. Statistical learning by 8-month-old infants. Science 274(5294). 1926-1928. https://doi.org/10.1126/science.274.5294.1926.

Searle, John R. 1975. Indirect speech acts. In Peter Cole \& J. Morgan (eds.), Speech acts (syntax and semantics 3), 59-82. New York: Academic Press.

Stalnaker, Robert C. 1978. Assertion. In Pragmatics, 315-332. Brill.

Starr, William B. 2014. Mood, force and truth. ProtoSociology 31. 160-181. https://doi.org/10.5840/protosociology20143113.

Starr, William B. 2020. A preference semantics for imperatives. Semantics and Pragmatics 13. 6. http://dx.doi.org/10.3765/sp.13.6.

Woodward, Amanda L. 1998. Infants selectively encode the goal object of an actor's reach. Cognition 69(1). 1-34. https://doi.org/10.1016/S0010-0277(98)00058-4. 